\title{
Transformation of Ammonium Dicyanamide into Dicyandiamide in the Solid
}

\author{
Barbara Jurgens, Henning A. Höppe, Elisabeth Irran, and Wolfgang Schnick* \\ Department Chemie, Ludwig-Maximilians-Universität München, Butenandtstrasse 5-13 (D), \\ D-81377 München, Germany
}

Received June 18, 2002

Ammonium dicyanamide $\mathrm{NH}_{4}\left[\mathrm{~N}(\mathrm{CN})_{2}\right]$ was synthesized through aqueous ion exchange. The crystal structure was investigated by single-crystal X-ray diffraction $\left(P 2_{1} / c, a=378.67(6) \mathrm{pm}, b=\right.$ 1240.9(3) pm, $\left.c=911.84(14) \mathrm{pm}, \beta=91.488(18)^{\circ}, Z=4\right)$. It derives from the $\mathrm{CsCl}$ structure type. Medium strong hydrogen bonds between $\mathrm{NH}_{4}^{+}$and $\left[\mathrm{N}(\mathrm{CN})_{2}\right]^{-}$ions are indicative of the observed formation of dicyandiamide $\mathrm{H}_{4} \mathrm{C}_{2} \mathrm{~N}_{4}$ during heating. According to DSC and temperature-dependent $X$-ray powder diffractometry, this isomerization is exothermic and occurs between 102 and $106^{\circ} \mathrm{C}$ in the solid. The reaction represents the isolobal analogue to the classical synthesis of urea by heating $\mathrm{NH}_{4} \mathrm{OCN}$. While other alkali and alkaline earth dicyanamides undergo trimerization or polymerization of their anions during heating, ammonium dicyanamide thus shows a different reactivity.

In the past few years the transition metal dicyanamides $\mathrm{M}^{\mathrm{II}}\left[\mathrm{N}(\mathrm{CN})_{2}\right]_{2}\left(\mathrm{M}^{\mathrm{II}}=\mathrm{Cr}, \mathrm{Mn}, \mathrm{Fe}, \mathrm{Co}, \mathrm{Ni}, \mathrm{Cu}\right)$ and coordination compounds containing $\left[\mathrm{N}(\mathrm{CN})_{2}\right]^{-}$ligands were investigated in detail because of their potential use as molecular magnets. ${ }^{1-3}$

Apart from this feature the thermal behavior of simple ionic dicyanamides was investigated. The occurring phase transitions were studied, and the varying reactivity of the dicyanamide ion was correlated with the cations involved: During heating the anions of the alkali dicyanamides $\mathrm{M}\left[\mathrm{N}(\mathrm{CN})_{2}\right]$ trimerize, forming the cyclic tricyanomelaminates $\mathrm{M}_{3}\left[\mathrm{C}_{6} \mathrm{~N}_{9}\right]$. Depending on the cation this reaction occurs in the solid $(\mathrm{M}=\mathrm{Na})^{4}$ or in the melt $\left(\mathrm{M}=\mathrm{K},{ }^{5} \mathrm{Rb},{ }^{5}\right.$ $\mathrm{Cs}^{6}$ ), respectively. For lithium dicyanamide a similar oligo-

\footnotetext{
* To whom correspondence should be addressed. E-mail: wolfgang.schnick@uni-muenchen.de.

(1) Manson, J. L.; Kmety, C. R.; Huang, Q.-Z.; Lynn, J. W.; Bendele, G. M.; Pagola, S.; Stephens, P. W.; Liable-Sands, L. M.; Rheingold, A. L.; Epstein, A. J.; Miller, J. S. Chem. Mater. 1998, 10, 2552.

(2) Manson, J. L.; Kmety, C. R.; Epstein, A. J.; Miller, J. S. Inorg. Chem. 1999, 38, 2552.

(3) Kurmoo, M.; Kepert, C. J. New J. Chem. 1998, 2, 1515.

(4) Jürgens, B.; Irran, E.; Schneider, J.; Schnick, W. Inorg. Chem. 2000, 39,665 .

(5) Irran, E.; Jürgens, B.; Schnick, W. Chem. Eur. J. 2001, 7, 5372.

(6) Jürgens, B.; Schnick, W. Unpublished results.
}

10.1021/ic025800k CCC: $\$ 22.00$ C 2002 American Chemical Society Published on Web 08/29/2002 merization of the anions or even a polymerization to products of hitherto unknown structure has been discussed. ${ }^{7}$

In contrast to the alkali dicyanamides the respective alkaline earth salts $\left(\mathrm{M}^{\mathrm{II}}=\mathrm{Mg}, \mathrm{Ca}, \mathrm{Sr}, \mathrm{Ba}\right)^{8}$ as well as the dicyanamides of other divalent metals $\left(\mathrm{M}^{\mathrm{II}}=\mathrm{Co}\right.$ and $\mathrm{Ni},{ }^{9}$ $\mathrm{Zn},{ }^{10} \mathrm{~Pb}^{11}$ ) do not show formation of the respective tricyanomelaminates $\mathrm{M}_{3}{ }_{3}\left[\mathrm{C}_{6} \mathrm{~N}_{9}\right]_{2}$. During thermolysis these salts form X-ray amorphous products and the FTIR spectra show broad signals indicating a further polymerization of the dicyanamide ions.

With regard to the reactivity of the dicyanamide ion depending on the cation as mentioned above, the thermal behavior of ammonium dicyanamide caught our interest. In the literature the synthesis of ammonium dicyanamide $\mathrm{NH}_{4}\left[\mathrm{~N}(\mathrm{CN})_{2}\right]$ and its IR and NMR spectra were mentioned, but structural data have not been reported as yet. ${ }^{12-14}$ Disagreeing information was available about the thermal behavior of $\mathrm{NH}_{4}\left[\mathrm{~N}(\mathrm{CN})_{2}\right]$ : Madelung et al. reported a melting point of $116^{\circ} \mathrm{C}$. Above $128^{\circ} \mathrm{C}$ the authors observed an evolution of ammonia and the formation of undefined polymeric products. ${ }^{12}$ Contrarily, Sprague et al. reported on the melting of $\mathrm{NH}_{4}\left[\mathrm{~N}(\mathrm{CN})_{2}\right]$ around $140{ }^{\circ} \mathrm{C}$. These authors postulated a reaction between $\mathrm{NH}_{4}{ }^{+}$and $\left[\mathrm{N}(\mathrm{CN})_{2}\right]^{-}$ions leading to the formation of dicyandiamide (cyanoguanidine) $\mathrm{H}_{4} \mathrm{C}_{2} \mathrm{~N}_{4}$ (eq 1). ${ }^{13}$ Furthermore, a thermally induced trimerization of the anions comparable to the situation of the alkali dicyanamides and formation of the tricyanomelaminate $\left(\mathrm{NH}_{4}\right)_{3}\left[\mathrm{C}_{6} \mathrm{~N}_{9}\right]$ might be possible.

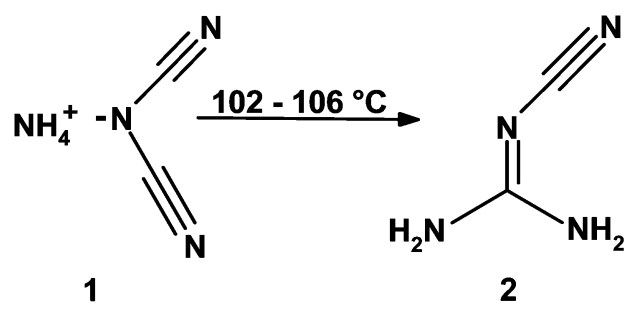

(eq. 1)

We synthesized ammonium dicyanamide $\mathrm{NH}_{4}\left[\mathrm{~N}(\mathrm{CN})_{2}\right]$ through ion exchange in aqueous solution starting from $\mathrm{Na}\left[\mathrm{N}(\mathrm{CN})_{2}\right]$ and $\mathrm{NH}_{4} \mathrm{Cl} .{ }^{15}$ According to the single-crystal

Inorganic Chemistry, Vol. 41, No. 19, 20024849 


\section{COMMUNICATION}

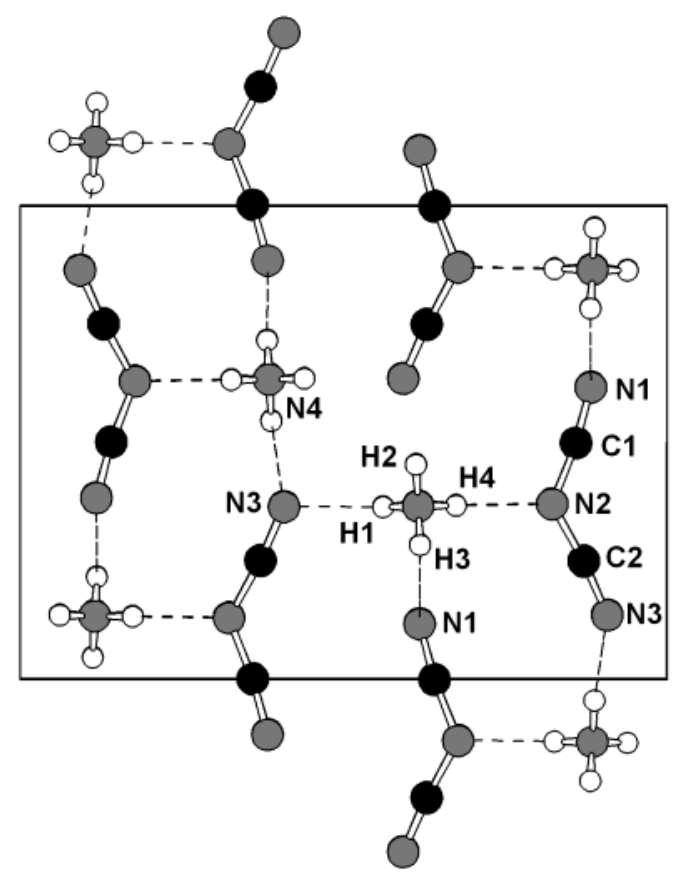

Figure 1. Crystal structure of $\mathrm{NH}_{4}\left[\mathrm{~N}(\mathrm{CN})_{2}\right]$, view along [100] (C, black; $\mathrm{N}$, gray; $\mathrm{H}$, white).

X-ray structure determination, $\mathrm{NH}_{4}\left[\mathrm{~N}(\mathrm{CN})_{2}\right]$ is built up from tetrahedral $\mathrm{NH}_{4}{ }^{+}$ions and bent planar $\left[\mathrm{N}(\mathrm{CN})_{2}\right]^{-}$ions (Figure 1). ${ }^{16}$ The $\mathrm{NH}_{4}{ }^{+}$ions are surrounded by the $\mathrm{N}$ atoms of eight $\left[\mathrm{N}(\mathrm{CN})_{2}\right]^{-}$ions forming a slightly distorted cube. Six terminal nitrogen atoms $(2 \times \mathrm{N} 1$ and $4 \times \mathrm{N} 3)$ as well as two bridging atoms $\mathrm{N} 2$ of the $\left[\mathrm{N}(\mathrm{CN})_{2}\right]^{-}$ions are involved in the coordination of the cation (Figure 2).

All of the hydrogen atoms have been localized during the structure determination. There are hydrogen bonds N4$\mathrm{H} 1 \cdots \mathrm{N} 3, \mathrm{~N} 4-\mathrm{H} 2 \cdots \mathrm{N} 3, \mathrm{~N} 4-\mathrm{H} 3 \cdots \mathrm{N} 1$, and $\mathrm{N} 4-\mathrm{H} 4 \cdots \mathrm{N} 2$ $(\mathrm{H} \cdots \mathrm{N}, 198-219 \mathrm{pm} ; \mathrm{N} 4 \cdots \mathrm{N}, 286-307 \mathrm{pm} ; \mathrm{N} 4-\mathrm{H} \cdots \mathrm{N}$,

(7) Purdy, A. P.; Houser, E.; George, C. F. Polyhedron 1997, 16, 3671.

(8) Jürgens, B.; Irran, E.; Schnick, W. J. Solid State Chem. 2001, 157, 241.

(9) Jürgens, B.; Kurmoo, M.; Schnick, W. Unpublished results.

(10) Manson, J. L.; Lee, D. W.; Rheingold, A. L.; Miller, J. S. Inorg. Chem. 1998, 37, 5966.

(11) Jürgens, B.; Höppe, H. A.; Schnick, W. Solid State Sci. 2002, 4, 821.

(12) Madelung, W.; Kern, E. Justus Liebigs Ann. Chem. 1922, 427, 1.

(13) Sprague, J. W.; Grasselli, J. G.; Ritchey, W. M. J. Phys. Chem. 1964, $68,431$.

(14) Kireeva, I. K.; Kharitonov, Y. Y.; Knyazeva, N. A.; Keller, K. Russ. J. Inorg. Chem. 1978, 23, 653.

(15) A column with an ion exchange resin (Merck, Ionenaustauscher I, Art. 4765) was completely filled with a solution of $\mathrm{NH}_{4} \mathrm{Cl}$ (Fluka, $\geq 99.5 \%$ (AT)). An excess of $\mathrm{NH}_{4} \mathrm{Cl}$ was removed by washing with water. Subsequently a solution of $\mathrm{Na}\left[\mathrm{N}(\mathrm{CN})_{2}\right]$ (Fluka, $\geq 96 \%$ (AT)) was poured onto the column. After evaporating of the water within some days at room temperature colorless needles of $\mathrm{NH}_{4}\left[\mathrm{~N}(\mathrm{CN})_{2}\right]$ were formed.

(16) For the structure determination a single crystal (size $0.50 \times 0.06 \times$ $0.05 \mathrm{~mm}^{3}$ ) was sealed inside a thin-walled glass capillary. X-ray diffraction data of 3620 reflections (953 independent, $R_{\text {int }}=0.0604$ ) in the range $5.4^{\circ} \leq 2 \theta \leq 55.0^{\circ}$ were collected on a STOE-IPDS diffractometer using graphite-monochromated $\mathrm{Mo} \mathrm{K} \alpha$ radiation $(\lambda=$ $71.073 \mathrm{pm}$ ) at a temperature of $T=200(2) \mathrm{K}$. The crystal structure of $\mathrm{NH}_{4}\left[\mathrm{~N}(\mathrm{CN})_{2}\right]$ was solved by direct methods using SHELXTL ${ }^{17}$ and refined with anisotropic displacement parameters for all atoms except the hydrogen atoms. Crystal data for $\mathrm{NH}_{4}\left[\mathrm{~N}(\mathrm{CN})_{2}\right]: M=84.09$ $\mathrm{g} \mathrm{mol}^{-1}, P 2{ }_{1} / c$ (No. 14), $a=378.67(6) \mathrm{pm}, b=1240.9$ (3) pm, $c=$ 911.84(14) pm, $\beta=91.488(18)^{\circ}, V=428.32(13) \times 10^{6} \mathrm{pm}^{3}, Z=4$, $\rho_{\text {calcd }}=1.304 \mathrm{~g} \mathrm{~cm}^{-3}, \mu=0.097 \mathrm{~mm}^{-1}, 72$ refined parameters, GOF $=0.816 ; R$ values for all data, $\mathrm{R} 1=0.0775, \mathrm{wR} 2=0.0893$.

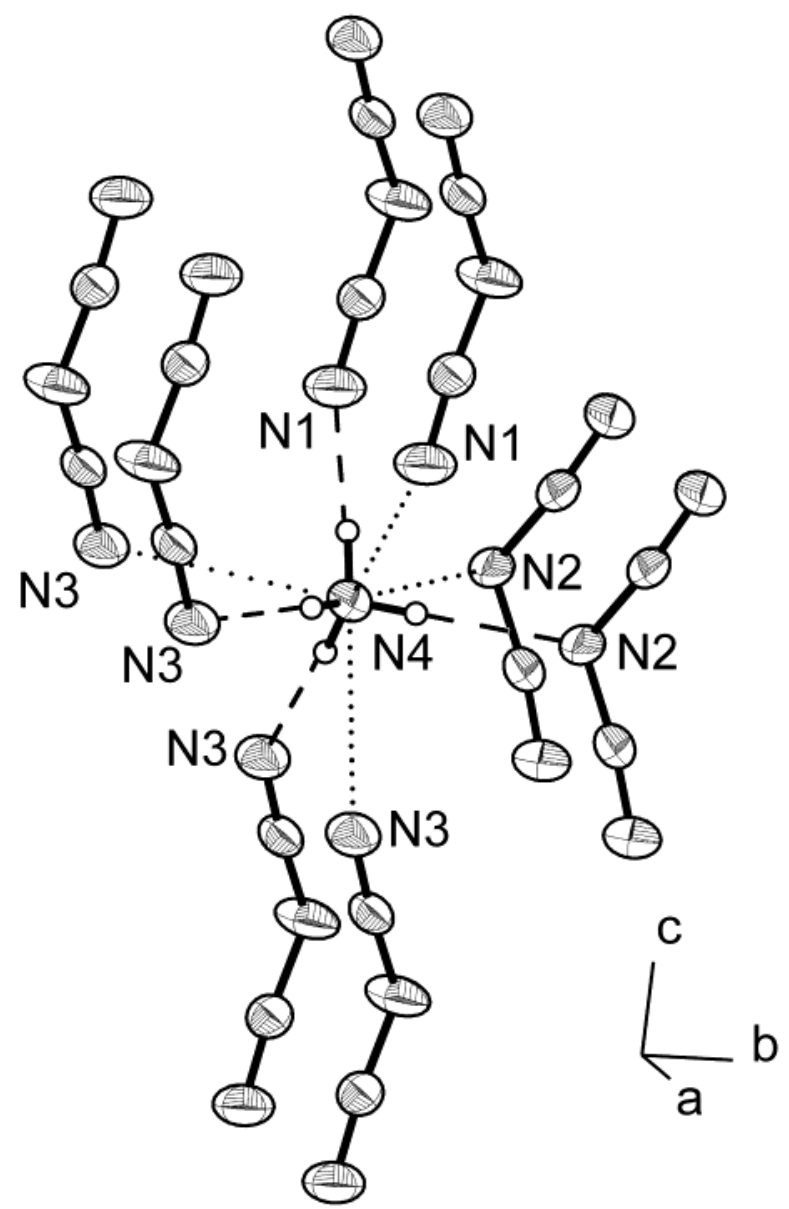

Figure 2. Coordination sphere of the $\mathrm{NH}_{4}{ }^{+}$ion in $\mathrm{NH}_{4}\left[\mathrm{~N}(\mathrm{CN})_{2}\right]$, with hydrogen bonds represented by broken lines; displacement ellipsoids are shown at the $70 \%$ probability level.

$\left.169-177^{\circ}\right)$; the distances agree well with those given in the literature for medium strong $\mathrm{N}-\mathrm{H} \cdots \mathrm{N}$ hydrogen bonds. ${ }^{18,19}$ The bond distances $\mathrm{C}-\mathrm{N}$ to the bridging $\mathrm{N}$ atoms in the anions $\left[\mathrm{N}(\mathrm{CN})_{2}\right]^{-}$are significantly longer $(131-132 \mathrm{pm})$ than those to the terminal $\mathrm{N}(115-116 \mathrm{pm})$, indicating single and triple bonds, respectively. The angles $\mathrm{N}-\mathrm{C}-\mathrm{N}$ are almost linear $\left(173-174^{\circ}\right)$, whereas the central angle $\mathrm{C}-\mathrm{N}-\mathrm{C}$ is $121^{\circ}$. These values are comparable to those of other dicyanamides. ${ }^{5,11}$

The crystal packing of cations and anions in $\mathrm{NH}_{4}\left[\mathrm{~N}(\mathrm{CN})_{2}\right]$ resembles that of the $\mathrm{CsCl}$ structure type. None of the known dicyanamides with monovalent cations $\mathrm{M}\left[\mathrm{N}(\mathrm{CN})_{2}\right](\mathrm{M}=$ $\mathrm{Na},{ }^{4} \mathrm{~K},{ }^{5} \mathrm{Rb},{ }^{5} \mathrm{Cs},{ }^{20} \mathrm{Ag}^{21,22}$ ) forms a similar structure. The crystal structure of $\alpha-\mathrm{K}\left[\mathrm{N}(\mathrm{CN})_{2}\right]$ derives from that of $\mathrm{KSCN}$ by a simple replacement of $\mathrm{N}$ by $\mathrm{NCN}$ and $\mathrm{S}$ by $\mathrm{N}$ in the $\mathrm{SCN}^{-}$ion. ${ }^{5}$ Contrarily, there is no evidence for a similar relation between the crystal structures of $\mathrm{NH}_{4} \mathrm{OCN}$ and $\mathrm{NH}_{4}\left[\mathrm{~N}(\mathrm{CN})_{2}\right]$.

(17) Sheldrick, G. M. SHELXTL, V5.10 Crystallographic System; Bruker AXS Analytical X-ray Instruments Inc.: Madison, 1997.

(18) Steudel, R. Chemie der Nichtmetalle, 2nd ed.; de Gruyter: Berlin and New York, 1998; pp 142 and 203.

(19) Steiner, T. Angew. Chem. 2002, 114, 50; Angew. Chem., Int. Ed. 2002 , $41,48$.

(20) Starynowicz, P. Acta Crystallogr. 1991, C47, 2198.

(21) Britton, D. Acta Crystallogr. 1990, C46, 2297.

(22) Britton, D.; Chow, Y. M. Acta Crystallogr. 1977, B33, 697. 


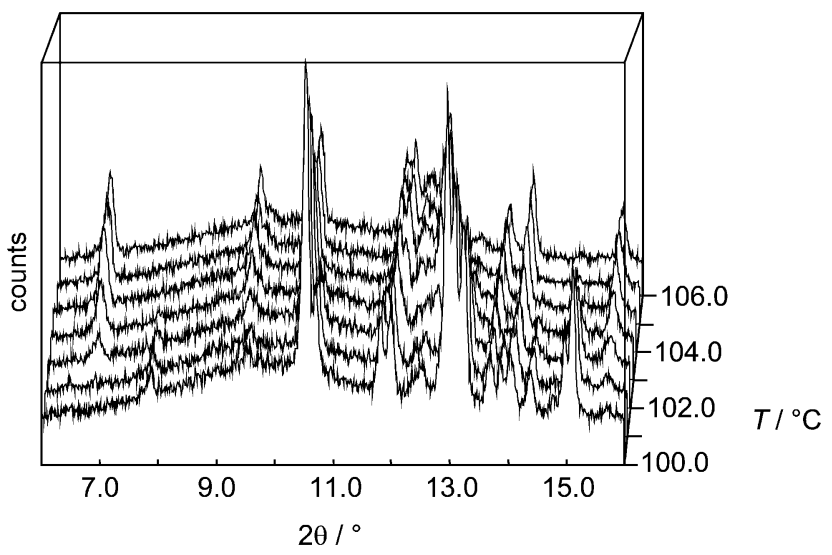

Figure 3. Temperature-dependent X-ray powder patterns of the phase transition of ammonium dicyanamide $\mathrm{NH}_{4}\left[\mathrm{~N}(\mathrm{CN})_{2}\right]$ into dicyandiamide $\mathrm{H}_{4} \mathrm{C}_{2} \mathrm{~N}_{4}\left(\mathrm{Mo} \mathrm{K} \alpha_{1}\right.$ radiation, $100-106{ }^{\circ} \mathrm{C}$ in steps of $\left.1{ }^{\circ} \mathrm{C}\right)$.

We performed thermoanalytical measurements and temperature-dependent X-ray powder diffraction experiments ${ }^{23}$ to investigate the thermal behavior of ammonium dicyanamide. The DSC curve exhibits a sharp exothermic signal at $138{ }^{\circ} \mathrm{C}$ indicating an irreversible reaction with $\Delta H \approx-10$ $\mathrm{kJ} \mathrm{mol}^{-1}$. This corresponds with a solid-solid phase transition between 102 and $106{ }^{\circ} \mathrm{C}$, which was identified by temperature-dependent X-ray powder diffraction (Figure 3). The temperature difference between both investigation methods is typical and presumably due to the much higher heating rate in the DSC experiment $\left(5^{\circ} \mathrm{C} \mathrm{min}{ }^{-1}\right)$. Neither the DSC experiment nor a visual inspection of the sample of $\mathrm{NH}_{4}\left[\mathrm{~N}(\mathrm{CN})_{2}\right]$ during heating gave any evidence for a melting process of the substance in this temperature range. Furthermore, according to the X-ray diffraction the sample never was X-ray amorphous. After heating to $108{ }^{\circ} \mathrm{C}$ and subsequent cooling to room temperature the pattern indicated that $\mathrm{NH}_{4}\left[\mathrm{~N}(\mathrm{CN})_{2}\right]$ quantitatively was transformed into dicyandiamide $\mathrm{H}_{4} \mathrm{C}_{2} \mathrm{~N}_{4}$. By further heating above $170{ }^{\circ} \mathrm{C}$ (Figure 4) the well-known transformation of dicyandiamide $\mathrm{H}_{4} \mathrm{C}_{2} \mathrm{~N}_{4}$ into melamine $\mathrm{H}_{6} \mathrm{C}_{3} \mathrm{~N}_{6}$ was observed. ${ }^{24}$

The powder diffraction patterns of the heated samples are in good agreement (Figure 4) with those simulated from structural data of dicyandiamide and melamine, respectively. ${ }^{25,26}$

The isomerization of $\mathrm{NH}_{4}\left[\mathrm{~N}(\mathrm{CN})_{2}\right]$ into dicyandiamide $\mathrm{H}_{4} \mathrm{C}_{2} \mathrm{~N}_{4}$ represents an analogue to Wöhler's classical synthesis of urea by heating $\mathrm{NH}_{4} \mathrm{OCN}:{ }^{27-30}$ The formal substitution of the $\mathrm{O}$ atom in $\mathrm{NH}_{4} \mathrm{OCN}$ by the isolobal ${ }^{31,32}$ cyanamide

(23) A differential scanning calorimetry (DSC) curve of $\mathrm{NH}_{4}\left[\mathrm{~N}(\mathrm{CN})_{2}\right]$ was recorded with a Mettler DSC 25 from 20 to $500{ }^{\circ} \mathrm{C}$ (heating rate: 5 ${ }^{\circ} \mathrm{C} \mathrm{min}^{-1}$ ). The temperature-dependent measurements between 100 and $120{ }^{\circ} \mathrm{C}$ were performed at atmospheric pressure on a STOE Stadi P powder diffractometer (Mo $\mathrm{K}_{1}$ radiation) in Debye-Scherrer geometry with a computer-controlled furnace in steps of $1{ }^{\circ} \mathrm{C}$.

(24) Bieling, H.; Radüchel, M.; Wenzel, G.; Beyer, H. J. Prakt. Chem. $1965,28,325$.

(25) Hirshfeld, F. L.; Hope, H. Acta Crystallogr. 1980, B36, 406.

(26) Varghese, J. N.; O'Connell, A. M.; Maslen, E. N. Acta Crystallogr. 1977, B33, 2102.

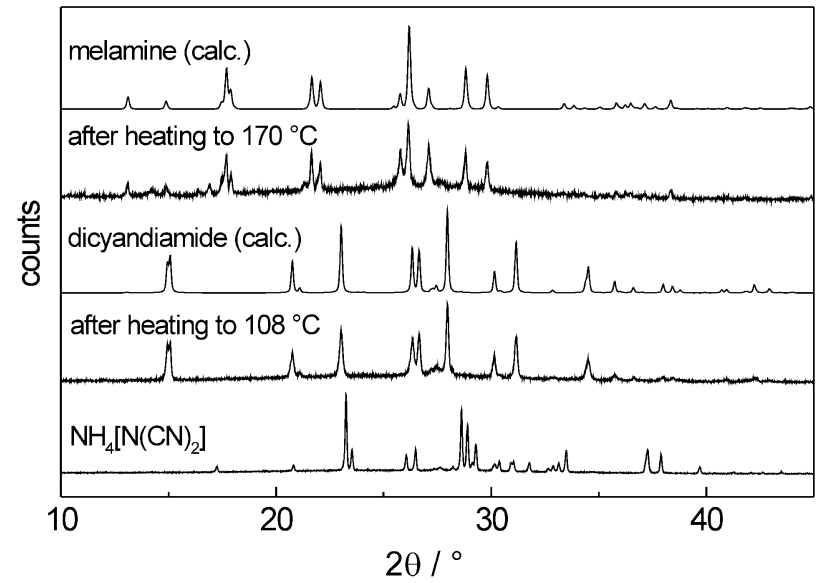

Figure 4. X-ray powder diffraction patterns $\left(\mathrm{Cu} \mathrm{K} \alpha_{1}\right.$ radiation, measured at room temperature) of $\mathrm{NH}_{4}\left[\mathrm{~N}(\mathrm{CN})_{2}\right]$ and its products after heating compared to diffraction patterns calculated from single-crystal diffraction data.

(carbodiimide) group $\mathrm{N}=\mathrm{C}=\mathrm{N}$ leads to ammonium dicyanamide $\mathrm{NH}_{4}\left[\mathrm{~N}(\mathrm{CN})_{2}\right]$. Both salts $\mathrm{NH}_{4} \mathrm{XCN}(\mathrm{X}=\mathrm{O}$, $\mathrm{NCN}$ ) undergo irreversible solid-solid transformations forming urea $\mathrm{H}_{4} \mathrm{CN}_{2} \mathrm{O}$ or dicyandiamide $\mathrm{H}_{4} \mathrm{CN}_{2}(\mathrm{NCN})$, respectively. In both cases no direct topological relation between the crystal structures of the ammonium salt $\mathrm{NH}_{4} \mathrm{XCN}$ and the respective isomerization product $\mathrm{H}_{4} \mathrm{CN}_{2} \mathrm{X}$ was found.

Further investigations are in progress to get a detailed picture of the mechanism of these solid-state transformations. ${ }^{33}$

Acknowledgment. Financial support by the Fonds der Chemischen Industrie, Germany, the Bundesministerium für Bildung und Forschung (Project 03-SC5 LMU-5), and especially by the Deutsche Forschungsgemeinschaft (Gottfried-Wilhelm-Leibniz-Programm) is gratefully acknowledged. The authors would like to thank Dr. P. Mayer (Department Chemie, LMU München) for the single-crystal data collection as well as S. Schmid and W. Wünschheim (Department Chemie, LMU München) for the thermoanalytical measurements. The authors are indebted to Prof. Dr. H. Zipse (Department Chemie, LMU München) for valuable discussions.

Supporting Information Available: Listings of the positional and thermal parameters, bond lengths and bond angles of $\mathrm{NH}_{4}\left[\mathrm{~N}(\mathrm{CN})_{2}\right]$ in $\mathrm{CIF}$ format. This material is available free of charge via the Internet at http://pubs.acs.org.

\section{IC025800K}

(27) Wöhler, F. Pogg. Ann. 1828, 12, 253.

(28) Liebig, J.; Wöhler, F. Ann. Phys. Leipzig, Ser. 2 1830, 20, 369.

(29) Cohen, P. S.; Cohen, S. M. J. Chem. Educ. 1996, 73, 883.

(30) Dunitz, J. D.; Harris, K. D. M.; Johnston, R. L.; Kariuki, B. M.; MacLean, E. J.; Psallidas, K.; Schweizer, W. B.; Tykwinski, R. R. J. Am. Chem. Soc. 1998, 120, 13274.

(31) Jäger, L.; Kretschmann, M.; Köhler, H. Z. Anorg. Allg. Chem. 1992, 611,68 .

(32) Hoffmann, R. Angew. Chem. 1982, 94, 725; Angew. Chem., Int. Ed. Engl. 1982, 21, 711.

(33) Lotsch, B.; Senker, J.; Schnick, W. In preparation. 